\title{
Acne inversa goes an extra mile than hidradenitis suppurativa
}

\author{
Henryk Witmanowski ${ }^{1,2}$, Paweł Szychta ${ }^{1,3}$, Sławomir Stępniewski ${ }^{1}$, Małgorzata Mackiewicz-Wysocka4, \\ Łucja Czyżewska-Majchrzak², Agnieszka Wasilewska ${ }^{5}$
}

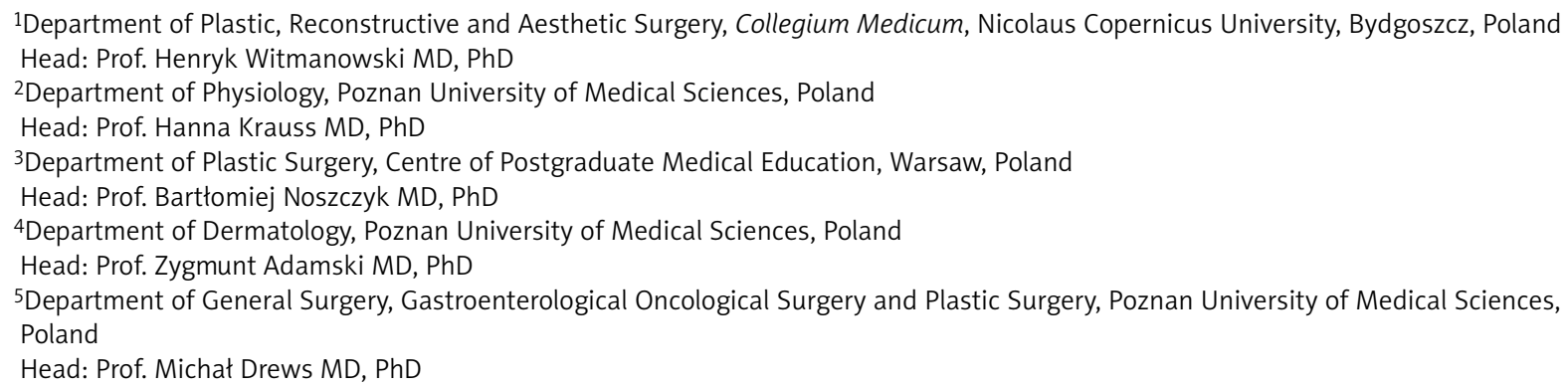

\begin{abstract}
Acne inversa (Al, hidradenitis suppurativa, Velpeau's disease, Verneuil's disease) is a severe, chronic inflammatory dermatosis of unknown etiology, detected on the basis of clinical symptoms more frequently in women than in men. Purulent lesions in the form of nodules and inflammatory tumors, fistulas and scars are present in the areas with hair follicles and apocrine glands, most commonly on the armpits, groin, around the anus and pubic region. Acne inversa can lead to physical and mental disorders. Unfortunately, it is often misdiagnosed and ineffectively treated. The paper presents a case of a 46-year-old patient who was successfully treated surgically for Al around the anus and buttocks by excision of the changes and closure of the wound with local flaps and split-thickness skin grafts, taken with dermatome from the rear surface of the thighs. Surgical treatment is the method of choice in the treatment of severe Al.
\end{abstract}

Key words: hidradenitis suppurativa, acne inversa, Velpeau's disease, Verneuil's disease, surgical treatment.

\section{Introduction}

Acne inversa (Al, hidradenitis suppurativa Velpeau's disease, Verneuil's disease, L73.2 in ICD-10) is an inflammatory dermatosis diagnosed on the basis of clinical symptoms with a prevalence from $0.1 \%$ to $4.1 \%$ and with a female-to-male ratio of $3: 1$ [1-3]. The chronic disease has the usual onset after puberty and progresses from noninflamed nodules to recurrent, multifocal, painful, rounded and deep abscesses, sinus tracts with suppurative discharge, intermittent with irregular scarring [4]. Acne inversa lesions are concentrated in the intertriginous areas with hair follicles and apocrine glands, including the axillary (Figures 1 and 2), inguinal, perianal (Figure $3 \mathrm{~A}$ ), perineal, but- tock, mammary, inframammary, chest, scalp, retroauricular and eyelid regions [5].

Acne inversa leads to intense long-term physical and psychological distress, which leads to familiar and professional disturbances [6]. Unfortunately, the disorder is commonly misdiagnosed or treated unsuccessfully with non-surgical measures.

This article aims to present a clinical problem of Al and to propose standards of treatment.

\section{Case report}

Patient 46 years old, smoking one pack of cigarettes per day, with a body mass index (BMI) of $20.96 \mathrm{~kg} / \mathrm{m}^{2}$ was

Address for correspondence: Prof. Henryk Witmanowski MD, PhD, Department of Plastic, Reconstructive and Aesthetic Surgery, Collegium Medicum, Nicolaus Copernicus University, 9-11 M. Sklodowska-Curie St, 85-094 Bydgoszcz, Poland, phone: +48 5258540 17, e-mail: hewit7@wp.pl Received: 15.04.2013, accepted: 11.07.2013. 


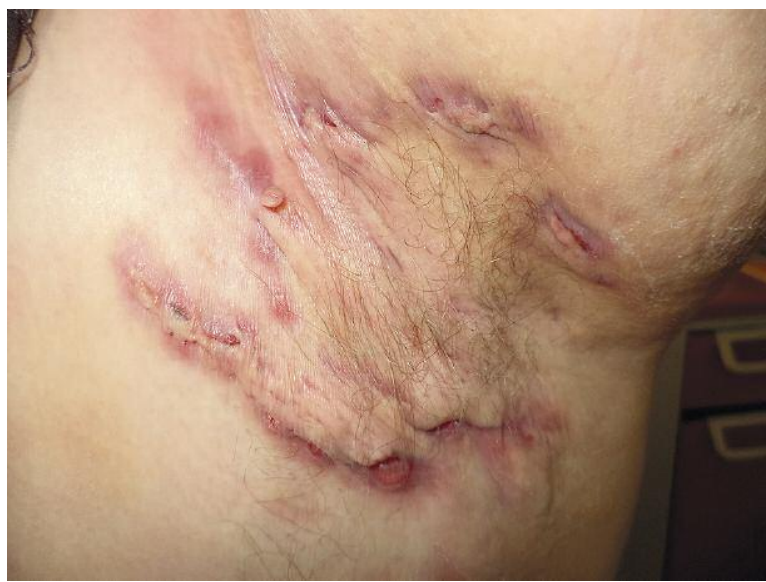

Fig. 1. Patient 1, aged 47, axillary location of Al (own collection)

\section{A}

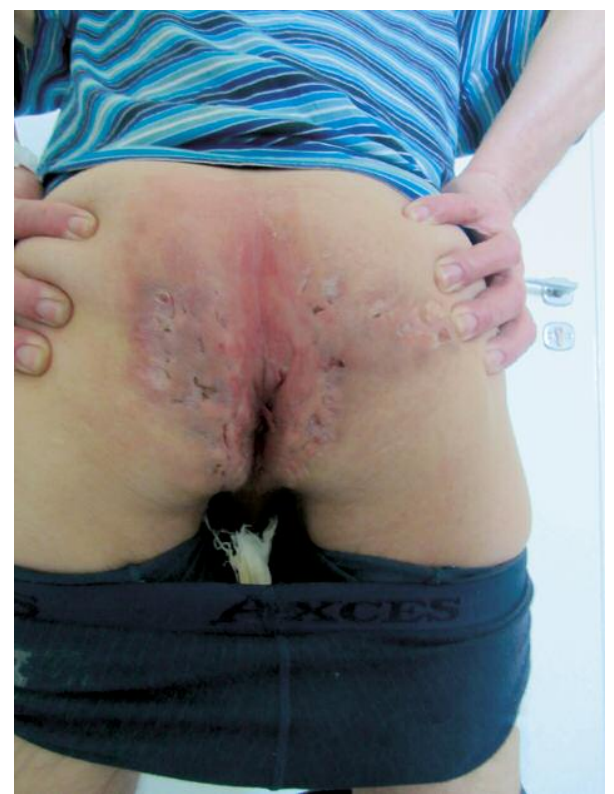

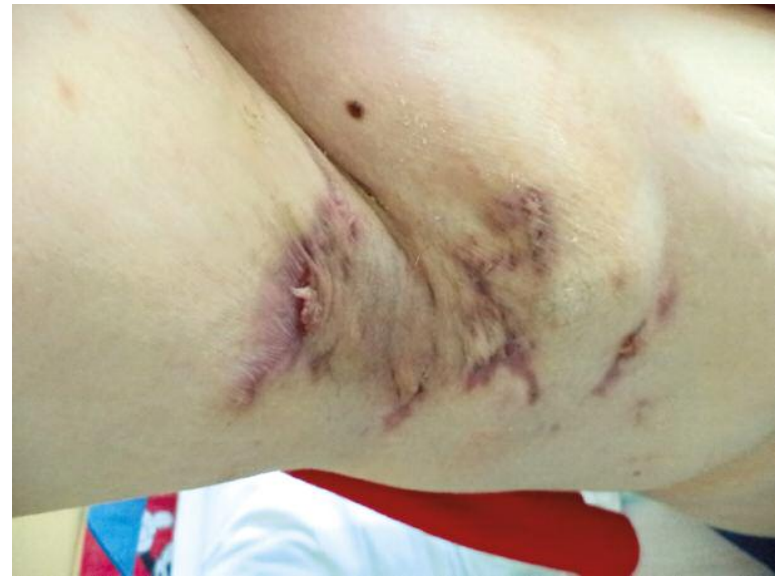

Fig. 2. Patient 2, aged 38, axillary location of Al (own collection)

\section{B}

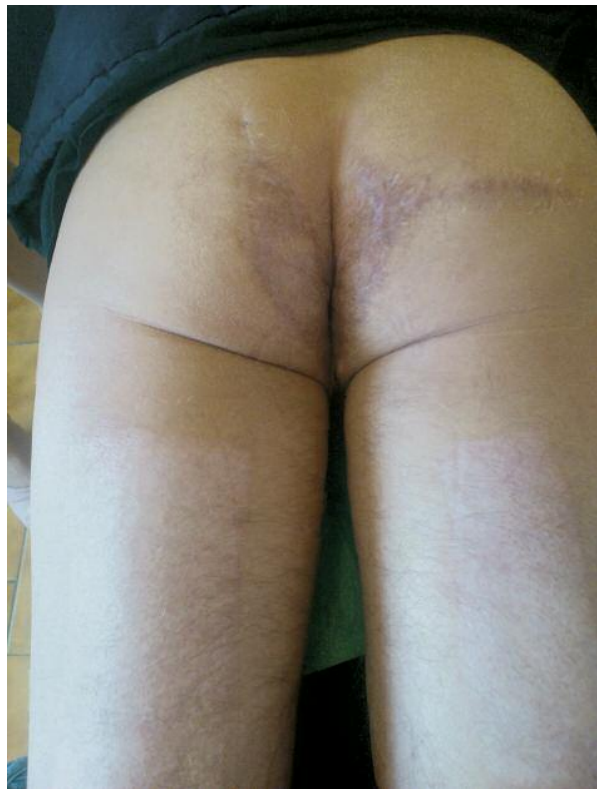

Fig. 3. Patient 3, aged 46, perianal location of Al: A - before surgical treatment, B - after surgical treatment

referred to the Clinic of Plastic Surgery in Bydgoszcz in January 2012, because of painful, hard lumps of both buttocks, pus, with a number of fistulas and scars in the skin (Figure 3). First symptoms appeared in mid-2007 but the patient did not search for medical advice because of the feeling of embarrassment. In early 2009 , he was consulted by a dermatologist and was treated unsuccessfully in the Dermatologic Clinic with oral dalacin C and metronidazole used for the first 2 weeks, followed by oral isotretinoin and aknenormin for 8 months prior to the use of oral metronidazole and tetracycline for the next 6 months. In the meantime, the disease significantly decreased his quality of private, social and professional life as a result of the foul smell associated with the disease and the constant necessity of the dressing changes.
In March 2012, a wide excision of fistulas, granulation tissues, scars of both buttocks, skin around the anus and a margin of clinically unchanged tissues was performed in the Department of Plastic, Reconstructive and Aesthetic Surgery in Bydgoszcz. Under general anesthesia and local infiltration with lignocaine, fistulas stained with pioctanine, scarred changes, granulations and the deep fistula penetrating into the rectum at the left side were all excised. The resulting loss of tissues was covered with local flaps and split skin grafts, taken with dermatome from the rear surface of the thighs. Hemostasis and layered stitching was performed.

The histopathological and immunohistochemical examination revealed pilonidal cysts of both buttocks. The cross-sectional study showed prevalent sinus tracts and 

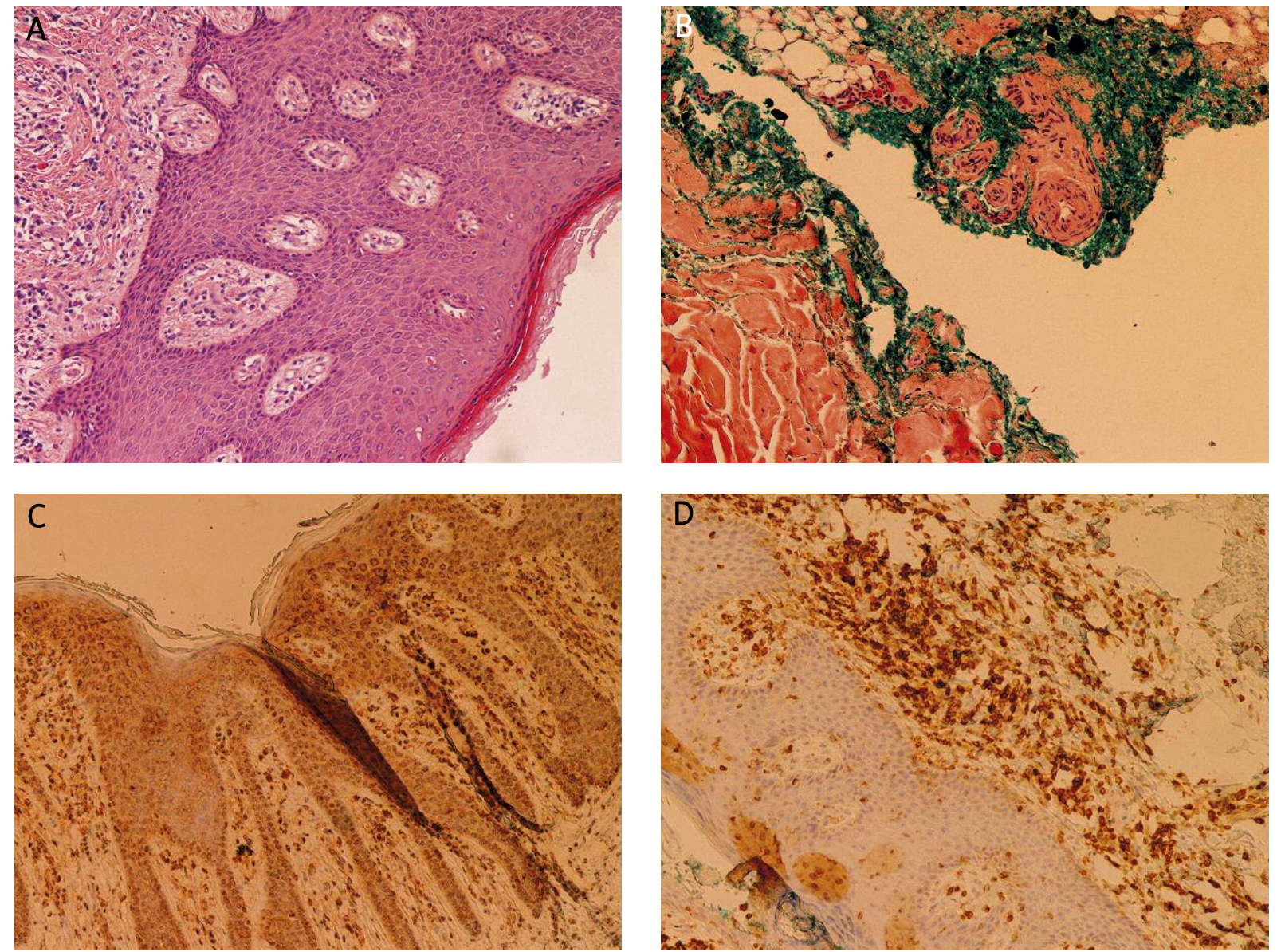

Fig. 4. Histopathological study: A - staining: $H+E$, magnification 100x; B-D - staining: immunohistochemical (B, D - magnification 100×, C-magnification 10x)

capsular changes in diameter from $0.5 \mathrm{~cm}$ to $1.5 \mathrm{~cm}$. In the stroma, mainly around the cysts, the current chronic inflammatory infiltration of the plasmatic cells CD138 + and the presence of lymphocytes $B(C D 20+)$ and $T(C D 3+)$ was observed (Figures 4 A-D).

In the postoperative period, there were no general or local complications. After a period of 3 weeks a complete healing was achieved and there has been no recurrence observed up to now. The significant improvement was seen in the patient's quality of life, with emphasis on the lack of the need of the dressing changes, no odor and the ease to maintain hygiene. The patient highlighted an important economical aspect of the treatment success, which was no further considerable expenditure for previously used drugs, treatments and the ruined underwear. Immediately after the procedure, the patient limited smoking to half a pack of cigarettes, and currently does not smoke at all.

\section{Discussion}

Until recently, the occlusion of the apocrine glandular duct caused by a keratin was claimed to result in $\mathrm{Al}$ [7].
Apocrinitis caused by the secondary infection led to rupture of the gland with the expansion of the infection into the adjacent follicles and subcutaneous fatty tissue [6]. However, the role of the apocrine gland in Al has been undermined [5].

Presently, it is suggested that Al is a primary disease of the hair follicles, spreading secondarily to the apocrine glands [8]. Previous detailed studies concerning histological abnormalities in Al revealed that occlusion of the terminal follicular epithelium, seen as spongiform inflammatory changes around the infundibulum, is manifested clinically as comedones and is a constant feature, regardless the disease duration [9-11]. Occlusion of the follicular infundibulum leads to dilatation and destruction of the follicle, which in turn results in spilling keratin and bacteria into the surrounding tissues [11-13]. The induced chemotactic response in the dermis includes firstly inflow of neutrophils, lymphocytes and histiocytes [5].

The resulting dermal abscess causes destruction of the pilosebaceous unit and the process extends secondly to the other adnexal structures [3]. Conclusively, the term "hidradenitis" should be modified to the more precise 
description of "acne inversa". Tissue repair ends up with fibrosis and sinus tracts, which are regarded as a typical feature of Al. In summary, the histological changes of the long-term Al include foreign dermal abscesses, body giant cells, fibrosis and sinus tracts $[14,15]$.

The progression of the disease has been classified by Hurley into three stages: stage I (abscesses without sinus tracts or scars), stage II (sinus tracts and scars with discrete recurrent abscesses) and stage III (diffuse and interconnected sinus tracts, scars, and abscesses) [16].

Several factors contribute to the development or progression of Al. Bacterial infection aggravates symptoms of Al and is secondary to chronic sinus tracts and moisture [17]. Microbiological swabs taken from superficial lesions are usually negative, whereas aspirates from deep lesions reveal different bacteria: Staphylococci, Streptococci, Peptostreptococci, Propionibacterium acnes, Escherichia coli, Bilophila wadsworthia and anaerobes [18-22].

The hormonal aspect of etiology, suggesting mostly the potential androgen effect, was not confirmed in other studies [23-26]. Coexistence was previously found between a peak incidence of $\mathrm{Al}$ in the second and third decades and the increase in androgen levels after puberty [5]. However, apocrine glands, previously thought to be the primary cause of Al, are insensitive to androgens [27]. In obese people, mechanical irritation, occlusion and maceration at skin folds can secondarily exacerbate the onset of Al [28]. Genetic load is believed to be a predisposing factor but no responsible genes have been defined [29]. Additionally, some external factors, including few medications (such as oral contraceptives, lithium and sirolimus) were reported to exacerbate the disease [30-32]. Smoking increases the risk of Al [33, 34]. However, no casual factors, such as deodorants, depilatory products or shaving, were reported to have a definitive effect on initiation of the disease [35].

Acne inversa is associated with various dermatologic syndromes, including: a) keratitis-ichthyosis-deafness, b) synovitis-acne-pustulosis-hyperostosis-osteitis syndrome, c) Crohn's syndrome, and is associated with a higher incidence of d) acne conglobata, e) dissecting cellulitis of the scalp and f) pilonidal sinus [5, 9]. Acne conglobata, dissecting cellulitis of the scalp and Al are components of the "follicular triad" [36]. Patients with chronic Al lesions have a higher risk of cancer, with an increased overall risk of 1.5 , including a higher risk of 4.6 of skin cancers other than melanoma, especially squamous cell carcinoma $[37,38]$.

Differential diagnosis includes: inflamed pilonidal cysts, staphylococcosis, carbuncles, lymphadenitis, infected Bartholin's or sebaceous cysts, steatocystoma multiplex syndrome and other sinus and fistula-producing diseases (tuberculosis, actinomycosis, lymphogranuloma venereum, inguinal lymphatic granulomatosis and ulcerative colitis) [3, 4, 6, 39].

The clinical diagnosis must be followed by a detailed interview about the possible symptoms of Al affecting quality of life. Patients usually present with painful, firm nod- ules, following the initial symptoms of chronic discomfort, pain, pruritus, erythema and hyperhidrosis. Fibrosis causes contracting scars with decreased mobility of limbs [3]. Sinus tracts can develop into fistula in the perianal or perineal regions. Contracting or disfiguring scars are esthetically unacceptable to patients [5]. Acne inversa presents with arthropathy syndromes and the associated symptoms of the joints [40]. The recurrent painful abscesses rupture spontaneously and release a malodorous discharge, and thus they lead to problems with hygiene as they require regular and frequent change of dressings [41]. As a result, Al has a detrimental effect on the quality of life [42]. Acne inversa is a physically and psychologically disabling disease, which leads to potential failed relationships, social isolation and depression [43]. As stated in the previous report, patients with Al at stage I or II lost on average 2.7 days of work per year due to exacerbation of symptoms [44].

Because of the rare spontaneous resolution of Al symptoms, treatment is required in order to reestablish the function and aesthetic appearance in the affected area and to improve the patient's quality of life [10]. Patients with Al are treated by surgeons, plastic surgeons, dermatologists, gynecologists, internists, infectious diseases physicians and immunologists [3]. During the first consultation, the physician should recommend temporary general measures, such as antiseptic soaps, tea tree oil, cotton underwear, loose clothing, soft brassieres, hold-up stockings and frequent change of dressings, all of which are useful to keep hygiene [3]. It must be noted, however, that all the conservative measures of treatment are not curative and provide only relief of symptoms $[40,45]$. They include topical use of disinfectants, zinc peroxide paste, acetate of aluminum, intralesional corticosteroids, retinoids, as well as systemic therapy with estrogens, androgens, antibiotics (penicillin, ciprofloxacin, tetracycline, chloramphenicol and erythromycin) [6]. Therefore, long-term non-surgical management is not recommended as it can lead to the disease progress into more advanced stages.

As the conservative therapies are not curative, surgery is the treatment of choice in cases at all stages of advancement [46-48]. Incision and drainage of abscesses should be limited to acute cases of Al. Local excision and primary closure of lesions has a relatively high rate of recurrence [10].

In contrast, a wide local excision with lateral margins from $5 \mathrm{~mm}$ up to $2 \mathrm{~cm}$ and deep margin to fascia ensures adequate removal of appendageal structures and is a curative method of management, regardless of the type of closure of the defect $[3,49]$. Any potential fistulas must be identified and excised [6]. With the above protocol of treatment, recurrence of Al treated with a radical excision was described as 3\% for axilla, 0\% for perianal region, 37\% for inguinoperineal and 50\% submammary regions after the follow-up from 3 to 72 months [50].

The type of the defect closure after the Al resection does not determine the risk of relapse, however, it significantly affects the aesthetics of the operated area. Healing by 
secondary intention is still recommended by some clinicians, however in our opinion it is usually too prolonged with a considerable risk of infection and results in extensive and unaesthetic scarring [27]. Whenever possible, direct closure of a relatively small skin defect is preferred. This can be performed in larger areas after undermining of the wound edges, which broadens the spectrum of potential clinical applications for a wider group of patients. However, primary closure in the female groin area can cause disfiguring labia deformities [2]. Split skin grafts are effective for larger defects, with well-known limitations and difficulties, and should be never considered for the skin covering joints [46]. Skin-subdermal and skin-fascial flaps are highly effective and provide more optimal aesthetic results when compared to the skin grafts [51-53]. Flaps have many advantages such as an early full recovery, rapid wound healing, no wound contractures and good aesthetic result [45]. The local flaps used for Al in the axilla were: Limberg flaps, transpositional flaps, $\mathrm{V}-\mathrm{Y}$ flaps, or perforator flaps [45, 51-55]. Defects in the groin area and buttocks were closed with local flaps: pedicled rectus abdominis musculocutaneous flap, medial thigh flap, superomedial thigh flap, $\mathrm{V}-\mathrm{Y}$ flap on the descending branch of the inferior gluteal artery, on the first perforator of the deep femoral artery and the descending branch of the inferior gluteal artery and bilobed flap on the descending branch or medial branch of the inferior gluteal artery [56-58]. Other measures include excision with a carbon dioxide laser, harmonic scalpel or radiation therapy.

\section{Conclusions}

Acne inversa is a common, chronic, dermatological entity, which highly affects quality of life. The disease is frequently misdiagnosed and mismanaged with conservative therapies, which can be considered only as a temporary measure. Radical surgical treatment provides the most reliable functional and aesthetic effects and prevents progression or recurrence of the disease.

\section{References}

1. Jemec JBE, Heidenheim M, Nielsen NH. The prevalence of hidradenitis suppurativa and its potential precursor lesions. J Am Acad Dermatol 1996; 35: 191-4.

2. Rieger UM, Erba P, Pierer G, Kalbermatten DF. Hidradenitis suppurativa of the groin treated by radical excision and defect closure by medial thigh lift: aesthetic surgery meets reconstructive surgery. J Plast Reconstr Aesthet Surg 2009; 62: 1355-60.

3. Jemec GB. Clinical practice. Hidradenitis suppurativa. N Engl J Med 2012; 366: 158-64.

4. Lee RA, Yoon A, Kist J. Hidradenitis suppurativa: an update. Adv Dermatol 2007; 23: 289-306.

5. Slade DE, Powell BW, Mortimer PS. Hidradenitis suppurativa: pathogenesis and management. Br J Plast Surg 2003; 56 : 451-61.
6. Bocchini SF, Habr-Gama A, Kiss DR, et al. Gluteal and perianal hidradenitis suppurativa: surgical treatment by wide excision. Dis Colon Rectum 2003; 46: 944-9.

7. Parks RW, Parks TG. Pathogenesis, clinical features and management of hidradenitis suppurativa. Ann R Coll Surg Engl 1997; 79: 83-9.

8. Shelley WB, Cahn MM. The pathogenesis of hidradenitis suppurativa in man: experimental and histologic observations. AMA Arch Derm 1955; 72: 562-5.

9. Attanoos RL, Appleton MAC, Douglas-Jones AG. The pathogenesis of hidradenitis suppurativa: a closer look at apocrine and apoeccrine glands. Br J Dermatol 1995; 133: 254-8.

10. Boer J, Weltevreden EF. Hidradenitis suppurativa or acne inversa. A clinicopathological study of early lesions. Br J Dermatol 1996; 135: 721-5.

11. Jemec GB, Hansen U. Histology of hidradenitis suppurativa. J Am Acad Dermatol 1996; 34: 994-9.

12. Pedraz J, Daudén E. Practical management of hidradenitis suppurativa. Actas Dermosifiliogr 2008; 99: 101-10.

13. Yu CC, Cook MG. Hidradenitis suppurativa: a disease of follicular epithelium, rather than apocrine glands. Br J Dermatol 1990; 122: 763-9.

14. Jansen T, Plewig G. What's new in acne inversa (alias hidradnitis suppurativa)? J Eur Acad Dermatol 2000; 14: 342-3.

15. Jansen T, Plewig G. Classification of suppurative hidradenitis. Hautarzt 1994; 45: 652-3.

16. Jemec GB, Faber M, Gutschik E, et al. The bacteriology of hidradenitis suppurativa. Dermatology 1996; 193: 203-6.

17. O'Loughlin S, Woods R, Kirke PN, et al. Hidradenitis suppurativa. Glucose tolerance, clinical, microbiologic, and immunologic features and HLA frequencies in 27 patients. Arch Dermatol 1988; 124: 1043-6.

18. Highet AS, Warren RE, Staughton RCD, et al. Streptococcus milleri causing treatable infection in perineal hidradenitis suppurativa. Br J Dermatol 1980; 103: 375-82.

19. Leach RD, Eykyn SJ, Phillips I, et al. Anaerobic axillary abscess. Br Med J 1979; 2: 5-7.

20. Till AE, Layton AM, Barth JH, et al. Staphylococcus lugdunensis isolated from axillary apocrine glands of hidradenitis suppurativa patients. J Invest Dermatol 1995; 104: 618.

21. Mortimer PS, Dawber RPR, Gales M, Moore RA. Mediation of hidradenitis suppurativa by androgens. Br Med J 1986; 292: 245-8.

22. Buczaj A, Pawlak H, Tarasińska J, et al. Evaluation of work conditions in a pasta manufacturing plant with particular consideration of dustiness. Ann Agric Environ Med 2012; 19: 810-6.

23. Harrison BJ, Read GF, Hughes LE. Endocrine basis for the clinical presentation of hidradenitis suppurativa. Br I Surg 1988; 75: $972-5$

24. Harrison BJ, Kumar S, Read GF, et al. Hidradenitis suppurativa: evidence for an endocrine abnormality. Br J Surg 1985; 72: 1002-4.

25. Jemec GB. The symptomotology of hidradenitis suppurativa in women. Br J Dermatol 1988; 119: 345-50.

26. Silverberg B, Smootm CE, Land SJ, Parsons RW. Hidradenitis suppurativa: patients satisfaction with wound healing by secondary intention. Plast Reconstr Surg 1987; 79: 555-9.

27. Jemec GBE, Heidenheim M. The influence of sex hormones on UVB induced erythema in man. J Dermatol Sci 1995; 9: 221-4.

28. Marinella MA. Lithium therapy associated with hidradenitis suppurativa. Acta Derm Venereol 1997; 77: 483.

29. Mahe E, Morelson E, Lechaton S, et al. Cutaneous adverse events in renal transplant recipients receiving sirolimus-based therapy. Transplantation 2005; 79: 476-82. 
30. Der Werth JM, Williams HC, Raeburn JA. The clinical genetics of hidradenitis suppurativa revisited. Br J Dermatol 2000; 142: 947-53.

31. Morgan WP, Leicester G. The role of depilation and deodarants in hidradenitis suppurativa. Arch Dermatol 1982; 118: 101-2.

32. Jemec GBE. Body weight in hidradenitis suppurativa. In: Acne and related disorders. Marks R, Plewig G (eds). Martin Dunitz, London 1989; 375-6.

33. Konig A, Lehmann C, Rompel R, et al. Cigarette smoking as a triggering factor of hidradenitis suppurativa. Dermatology 1999; 198: 261-4.

34. Fronczak A, Polańska K, Dziankowska-Zaborszczyk E, et al. Changes in smoking prevalence and exposure to environmental tobacco smoke among adults in Łódź, Poland. Ann Agric Environ Med 2012; 19: 754-61.

35. Wortsman XC, Holm EA, Wulf HC, et al. Real-time spatial compound ultrasound imaging of skin. Skin Res Technol 2004; 10: 23-31.

36. Hurley H. Axillary hyperhidrosis, apocrine bromhidrosis, hidradenitis suppurativa, and familial benign pemphigus. In: Dermatologic surgery. Roegnick RH, Roegnick HH (eds.). Marcel Dekker, New York 1989; 717-43.

37. Vasey FB, Fenske NA, Clement GB, et al. Immunological stud ies of the arthritis of acne conglobata and hidradenitis suppurativa. Clin Exp Rheumatol 1984; 2: 309-11.

38. Nakanishi M, Yokota K, Ochi M. Surgical management of hidradenitis suppurativa in the sub-mammary area. J Plast Reconstr Aesthet Surg 2010; 63: e177-9.

39. Bura M, Bura A, Adamek A, et al. Seroprevalence of hepatitis A virus antibodies (anti-HAV) in adult inhabitants of Wielkopolska region, Poland - the role of simple demographic factors. Ann Agric Environ Med 2012; 19: 738-41.

40. von der Werth J, Jemec GBE. Morbidity in patients with hidradenitis suppurativa. Br J Dermatol 2001; 144: 809-14.

41. Jemec GBE, Heidenheim M, Nielsen NH. Hidradenitis suppurativa: characteristics and consequences. Clin Exp Dermatol 1996; 21: 419-23.

42. Lapins J, YeW, Nyren O, et al. Incidence of cancer among patients with hidradenitis suppurativa. Arch Dermatol 2001; 137: $730-4$.

43. Świnoga M, Kłos M, Miniszewska J, Zalewska-Janowska A. Health-related quality of life in dermatological and allergodermatological patients. Postep Derm Alergol 2012; 29: 69-73.

44. Donsky HJ, Mendelson CG. Squamous cell carcinoma as a complication of hidradenitis suppurativa. Arch Dermatol 1964; 90: 488-91.

45. Rompel R, Petres J. Long-term results of wide surgical excision in 106 patients with hidradenitis suppurativa. Dermatol Surg 2000; 26: 638-43.

46. Lorenz D. Recurrent sweat gland abscess. Langenbecks Arch Chir Suppl Kongressbd 1997; 114: 490-2.

47. Kagan RJ, Yakuboff KP, Warner P, et al. Surgical treatment of hidradenitis suppurativa: a 10-year experience. Surgery 2005; 138: 734-40.

48. Ritz JP, Runkel N, Haier J, Buhr H. Extent of surgery and recurrence rate of hidradenitis suppurativa. Int J Colorectal Dis 1998; 13: 164-9.

49. Harrison BJ, Mudge M, Hughes LE. Recurrence after surgical treatment of hidradenitis suppurativa. Br Med J (Clin Res Ed) 1987; 294: 487-9.

50. Altmann S, Fansa H, Schneider W. Surgical treatment of axillary hidradenitis suppurativa. Chirurg 2001; 72: 1413e6.
51. Rehman N, Kannan RY, Hassan S, et al. Thoracodorsal artery perforator (TAP) type I V-Y advancement flap in axillary hidradenitis suppurativa. Br J Plast Surg 2005; 58: 441e4.

52. Chuang CJ, Lee CH, Chen TM, et al. Use of a versatile transpositional flap in the surgical treatment of axillary hidradenitis suppurativa. J Formos Med Assoc 2004; 103: 644e7.

53. Govindan KS, Rehman N, Vadodaria S, Hart NB. Use of lotus petal flap in the treatment of perineal hidradenitis suppurativa. Eur J Plast Surg 2006; 28: 486-9.

54. Schwabegger AH, Herczeg E, Piza H. The lateral thoracic fasciocutaneous island flap for treatment of recurrent hidradenitis axillaris suppurativa and other axillary skin defects. $\mathrm{Br}$ J Plast Surg 2000; 53: 676e8.

55. Geh JL, Niranjan NS. Perforator-based fasciocutaneous island flaps for the reconstruction of axillary defects following excision of hidradenitis suppurativa. Br J Plast Surg 2002; 55: $124 \mathrm{e} 8$.

56. Tanaka A, Hatoko M, Tada H, et al. Experience with surgical treatment of hidradenitis suppurativa. Ann Plast Surg 2001; 47: 636e42.

57. Kishi K, Nakajima H, Imanishi N. Reconstruction of skin defects after resection of severe gluteal hidradenitis suppurativa with fasciocutaneous flaps. J Plast Reconstr Aesthet Surg 2009; 62: 800-5.

58. Lockwood TE. Fascial anchoring technique in medial thigh lifts. Plast Reconstr Surg 1988; 82: 299-304. 